\title{
Study on Mechanical and Anticorrosion Performance of NiW Alloy Coatings Prepared by Induced Codeposition
}

\author{
Yuhan Hu, Yundan Yu*, Hongliang Ge, Guoying Wei, Li Jiang, \\ College of Materials Science and Engineering, China Jiliang University, Hang Zhou 310018, China \\ *E-mail: yuyundan@163.com
}

doi: $10.20964 / 2019.02 .19$

Received: 17 October 2018 / Accepted: 18 November 2018 / Published: 5 January 2019

\begin{abstract}
NiW alloy coatings were obtained from the acid solution with different concentrations of tungstate. Influences of tungsten contents on mechanical and anticorrosion performance of NiW alloy coatings were investigated. Tungsten cannot be directly deposited from aqueous solution. However, with the interaction of nickel ions, tungsten and nickel could be codeposited together considered as induced codeposition. The microstructure of $\mathrm{NiW}$ alloys coating is $\mathrm{Ni}_{17} \mathrm{~W}_{3}$ with face center cubic which is a kind of solid solution with nickel as solvent and tungsten as solute. Tungsten atoms occupy the lattice points of the nickel atoms and squeeze the nickel atoms to form lattice distortion resulting in the increase of hardness. NiW alloy coatings with higher tungsten content possess denser and compact nodular structures that contribute directly to the increase of anticorrosion performance.
\end{abstract}

Keywords: NiW alloy coatings; Electrodeposition; Anticorrosion;

\section{$\underline{\text { FULL TEXT }}$}

(C) 2019 The Authors. Published by ESG (www.electrochemsci.org). This article is an open access article distributed under the terms and conditions of the Creative Commons Attribution license (http://creativecommons.org/licenses/by/4.0/). 